"This is a post-peer-review, pre-copyedit version of an arti-
cle published in Structural Analysis of Historical Construc-
tions. The final authenticated version is available online at:
http://dx.doi.org/10.1007/978-3-319-99441-3".
Link the published version:
https://www.springer.com/gp/book/9783319994406

(C) 2019. This manuscript version is made available under the Creative Commons Attribution-NonCommercial-NoDerivs (CC BY-NC-ND) 4.0 International License

(Creative Commons Attribution Non-Commercial 4.0 International (CC BY-NC) 


\title{
A comparison between the bond behavior of SRP and SRG strengthening systems applied to a masonry substrate
}

\author{
Mattia Santandrea $^{1}$, Giulia Baietti ${ }^{2}$, Seyedmohammad Kahangi Shahreza ${ }^{3}$, and Christian Carloni ${ }^{4}$
}

\begin{abstract}
Strengthening and rehabilitation of existing masonry buildings is a topic that attracts the interest of the scientific community worldwide. Fiber reinforced polymer (FRP) composites have been largely employed for structural rehabilitation of masonry structures due to their ease of installation and their high strength-toweight ratio, since the end of the previous century. Recently, fiber reinforced cementitious matrix (FRCM) composites have become an appealing alternative to traditional FRPs, because they employ an inorganic matrix to embed the fibers, which provides a better vapor compatibility with masonry substrate and better resistance to high temperatures than FRPs. To reduce the cost of carbon and glass fibers, the use of new types of fibers, such as high strength steel cords, has been explored. Steel reinforced polymer (SRP) and steel reinforced grout (SRG) are still moving their first steps in the world of structural rehabilitation, but they have shown potentials to become a suitable alternative to other FRP and FRCM composites, respectively. In this work, SRP and SRG composites are bonded to masonry blocks and tested using a direct single-lap shear test set-up to investigate the debonding phenomenon. Two different types of mortar grout are employed for the SRG. A comparison between SRP and SRG composites is presented in terms of debonding capacity and failure modes.
\end{abstract}

Keywords: bond, masonry, SRG composites, SRP composites, shear tests.

\section{Introduction}

The study of innovative strengthening solutions able to reduce the vulnerability of existing masonry structures is an appealing field that focused the interest of the scientific community in the last decades. Several factors can determine the need for high strengthening performance of an existing masonry structure, such as a change of use of the building or the need to improve the response of the structure against natural hazards (e.g. earthquakes). For reinforced concrete buildings, code requirements are usually aimed at preventing the collapse of the entire reinforced concrete skeleton; while, for masonry buildings code requirements are principally aimed at avoiding the local failure mechanisms that generally involved only a portion of the building. Among the new strengthening solutions developed to prevent the local failure of masonry substructures, a relevant success was obtained by fiber reinforced polymer (FRP) composites and by fiber reinforced cementitious matrix (FRCM) composites.

\footnotetext{
${ }^{1} \mathrm{PhD}$ student, Department of Civil, Chemical, Environmental, and Materials Engineering, DICAM, University of Bologna, Bologna, Italy, mattia.santandrea3@unibo.it

${ }^{2}$ PhD student, Department of Civil, Chemical, Environmental, and Materials Engineering, DICAM, University of Bologna, Bologna, Italy, giulia.baietti2@unibo.it

${ }^{3}$ Research fellow, Department of Civil, Chemical, Environmental, and Materials Engineering, DICAM, University of Bologna, Bologna, Italy, seyedmohamma.kahangi@studio.unibo.it

${ }^{4}$ Associate Professor, Department of Civil, Chemical, Environmental, and Materials Engineering, DICAM, University of Bologna, Bologna, Italy, christian.carloni@unibo.it
} 
FRP composites are comprised of high strength fibers embedded in a thermosetting matrix, while FRCM composites are comprised of high strength fibers embedded in a cementitious mortar. Both FRP and FRCM composites can provide several advantages when applied to existing masonry structures such as the ease of installation and a high strength-to-weight ratio. In addition, FRCM composites offered also a good vapor compatibility with masonry substrate and a good resistance to elevated temperatures. Recently, newly developed composite materials that employ low cost high strength steel fibers instead of more expansive carbon, glass or aramid fibers, were used for strengthening purposes. These new materials are known as steel reinforced polymer (SRP) composites, when a thermosetting matrix is employed, or steel reinforced grout (SRG) composites, when a mortar grout is used. Different research groups investigated the bond behavior of SRP [1] [2] [3] [4] and SRG [5] [6] [7] [8] systems applied to a masonry substrate or to a brick.

This work presents the results of direct single-lap shear tests performed on both SRP and SRG composites bonded to a masonry substrate. Two different mortar matrices were employed for the SRG composites, i.e. a lime-based mortar and a cement-based mortar. A comparison between SRP and SRG composites is presented in terms of debonding capacity and failure modes.

\section{Methods}

\subsection{Materials}

The masonry blocks were made of solid clay bricks and a low strength mortar. Twenty cylinders were cored from five half-bricks extracted from the masonry blocks after the direct shear tests were performed. The nominal dimensions of the cylinders were equal to $50 \mathrm{~mm}$ (diameter) $\times 50 \mathrm{~mm}$ (length). Out of twenty cylinders, seven were used to determine the tensile strength of bricks, $f_{b t}$, through splitting tests, while thirteen were used to obtain the compressive strength of bricks, $f_{b c}$, according to [9]. The tensile strength of bricks, $f_{b t}$, resulted equal to $3.16 \mathrm{MPa}\left(\mathrm{CoV}\right.$ 0.12), while the compressive strength of bricks, $f_{b c}$, resulted equal to $20.3 \mathrm{MPa}(\mathrm{CoV} 0.17)$. The composite strip bonded to the masonry blocks was comprised of high strength steel fibers embedded in thermosetting matrix, a lime-based mortar matrix, or a cement-based mortar matrix. The steel fibers are in the form of a unidirectional sheet made of high strength galvanized twisted steel micro-cords held together by a glass fiber micro-mesh. Each micro-cord consists of five filaments. Three of the five filaments are straight, and the remaining two filaments are wrapped around the other three with a high torque angle. The cross-sectional area of the cord is $0.538 \mathrm{~mm}^{2}$. Masonry blocks were strengthened using two different densities of the fiber sheets. SRP specimens were strengthened using high density (HD) steel fiber sheets, while SRG specimens were strengthened using low density (LD) steel fiber sheets. The physical and mechanical properties of the steel fiber sheets provided by the manufacturer [10] are reported in Table 1. The epoxy matrix is a two-component epoxy thixotropic gel system, the lime-based mortar matrix is a hydraulic mortar made of lime and mineral binder with fine particle size, while the cement-based mortar is a cementitious grout developed for concrete and 
masonry substrates. The properties of the three different matrices as reported by manufacturer [10] are presented in Table 2.

Table 1. Physical and mechanical properties of the steel fibers (provided by the manufacturer [10]).

\begin{tabular}{|c|c|c|}
\hline Steel Fiber sheet density & LD & HD \\
\hline Tensile strength [MPa] & $>3000$ & $>3000$ \\
\hline Elastic Modulus [GPa] & $>190$ & $>190$ \\
\hline Break deformation [\%] & $>2$ & $>2$ \\
\hline Number of cords/mm & 0.156 & 0.472 \\
\hline Equivalent thickness [mm] & $t_{f, L D} 0.084$ & $t_{f, H D} 0.254$ \\
\hline
\end{tabular}

Table 2. Mechanical properties of the matrices (provided by the manufacturer [10]).

\begin{tabular}{|c|c|c|c|c|}
\hline Type of matrix & $\begin{array}{c}\text { Compressive strength } \\
(28 \text { days }) \\
{[\mathrm{MPa}]}\end{array}$ & $\begin{array}{c}\text { Modulus of } \\
\text { Elasticity } \\
{[\mathrm{GPa}]}\end{array}$ & $\begin{array}{c}\text { Tensile strength } \\
(28 \text { days }) \\
{[\mathrm{MPa}]}\end{array}$ & $\begin{array}{c}\text { Shear strength } \\
{[\mathrm{MPa}]}\end{array}$ \\
\hline Epoxy matrix & $/$ & 5.3 & $/$ & 20 \\
\hline Lime-based matrix & 15 & 9 & 5 & $/$ \\
\hline Cement-based matrix & 50 & 20 & 8 & $/$ \\
\hline
\end{tabular}

\subsection{Test procedure}

Three SRP-masonry joints and eight SRG-masonry joints were tested using a single-lap shear test set-up. SRP specimens where strengthened using HD steel fibers embedded in an epoxy matrix. Out of eight SRG specimens, three were strengthened using LD steel fibers embedded in a lime-based mortar matrix, while five were strengthened using LD steel fibers embedded in a cement-based mortar matrix. The dimensions of all masonry blocks were $120 \mathrm{~mm}($ width $) \times 120 \mathrm{~mm}($ depth $) \times 380 \mathrm{~mm}$ (length). All composite strips were applied using a wet layup process, with a bonded width $\left(b_{f}\right)$ equal to $50 \mathrm{~mm}$ and a bonded length $(\boldsymbol{\ell})$ equal to $315 \mathrm{~mm}$. The thickness of the SRP strips was equal to $4 \mathrm{~mm}$, while the thickness of the SRG strips was equal to $8 \mathrm{~mm}$. The bonded area started approximatively $35 \mathrm{~mm}$ from the top edge (loaded end of the fibers) of the masonry block to avoid spalling of the first brick of the specimen. The fibers were arranged across the width of the reinforcement in order to have approximatively a distance between the external fibers of the grid and the edges of the matrix equal to half of the fiber spacing. For SRG specimens, the matrix was not applied outside of the bonded region, where fibers were left bare. For SRP specimens the epoxy matrix was applied to embed the fibers also in the unbonded region. Direct single-lap shear tests were conducted in displacement control. The classical push-pull configuration was adopted, where the steel fibers or the SRP strip were pulled, while the masonry blocks were restrained by a steel fixture (Fig. 1). For SRP specimens, the composite strip was directly clamped by the top grip of the testing machine, while for SRG specimens an epoxy tab was constructed to allow the clamping by the machine top grip. To ensure a uniform distribution of the load, neoprene sheets were placed between the square faces of the masonry block and the plates of the steel fixture. Two linear variable displacements transformers (LVDT) were mounted on the masonry surface close to the beginning of the bonded area. The LVDTs (named LVDT $\mathrm{a}$ and $\mathrm{b}$ in Figure 1) reacted off of a thin aluminum $\Omega$-shaped plate that was attached to the bare fiber surface (for SRG specimens) or to the epoxy surface (for SRP specimens) adjacent to the top edge of the bonded area. The average of the two LVDT measurements is named global slip $g$ in the reminder of this paper. SRG specimens were tested increasing the value of the global slip $g$ at a constant rate equal to $0.00084 \mathrm{~mm} / \mathrm{s}$, 
while SRP specimens were tested increasing the displacement of the stroke of the machine at a constant rate equal to $0.003 \mathrm{~mm} / \mathrm{s}$. Two additional LVDTs (LVDT $\mathrm{c}$ and d) measured the horizontal displacement of the masonry block in the direction perpendicular to the face of the composite strip. LVDT $\mathrm{c}$ and $\mathrm{d}$ were fixed to the bottom plate through magnets. The LVDTs reacted off the surface of the masonry block opposite to the one where the composite strip was applied. Specimens were named following the designation DS_A_B_Z, where A indicates the type of fibers ( $\mathrm{LD}=$ low density, $\mathrm{HD}=$ high density), $\mathrm{B}$ denotes the type of matrix ( $\mathrm{EM}=$ epoxy matrix, $\mathrm{LM}=$ lime-based matrix, $\mathrm{CM}=$ cement-based matrix), and $\mathrm{Z}=$ specimen number.

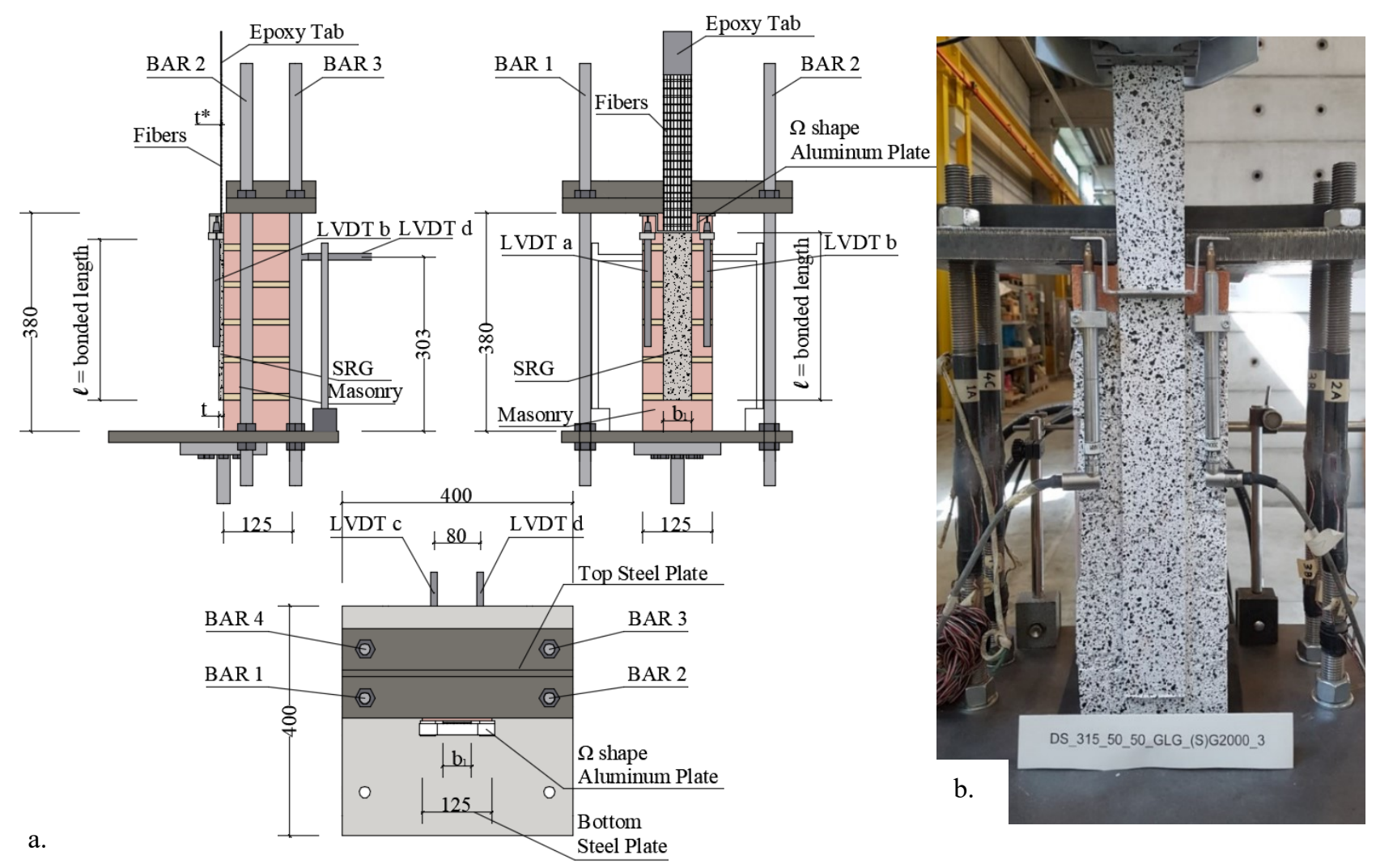

Figure 1. Single-lap direct shear test set-up: sketch (a) and photo (b).

\section{Results and failure modes}

The load responses in terms of applied load $P$ versus global slip $g$ are shown in Fig. 2a for SRP specimens and in Fig. $2 b$ for SRG specimens. All SRG load responses show an initial linear portion followed by a non-linear branch until the peak load, $P^{*}$, is reached. After the peak load is reached, the load response is characterized by a drop followed by a nominally constant branch (or plateau) until complete detachment of the composite occurred. The nominally constant load, $P_{\text {crit }}$, was evaluated as the average value of the load within the global slip range $\left[g_{1}, g_{2}\right]$. This range was directly determined on the load response. For each specimen the value of $g_{1}$ was determined as the global slip corresponding to the sudden drop in the load response, while the value of $g_{2}$ was determined as the global slip corresponding to the failure of the specimen. For SRP specimens, the behavior was slightly different with respect to the one observed for SRG specimens, due to the presence of the mortar 
joints that determined some drops in the load response during the debonding phenomenon [11]. It should be observed that for SRP specimens it was not possible to determine the first portion of the load response until the peak load, since the measurements of LVDT $a$ and $b$ were very small until debonding started. Although not confirmed by additional tests that are planned for the next campaign, the small displacement recorded by the LVDT could be related to the different surface of application of the $\Omega$-shaped plate, which was attached to the epoxy surface instead of to the bare fibers for SRP specimens.
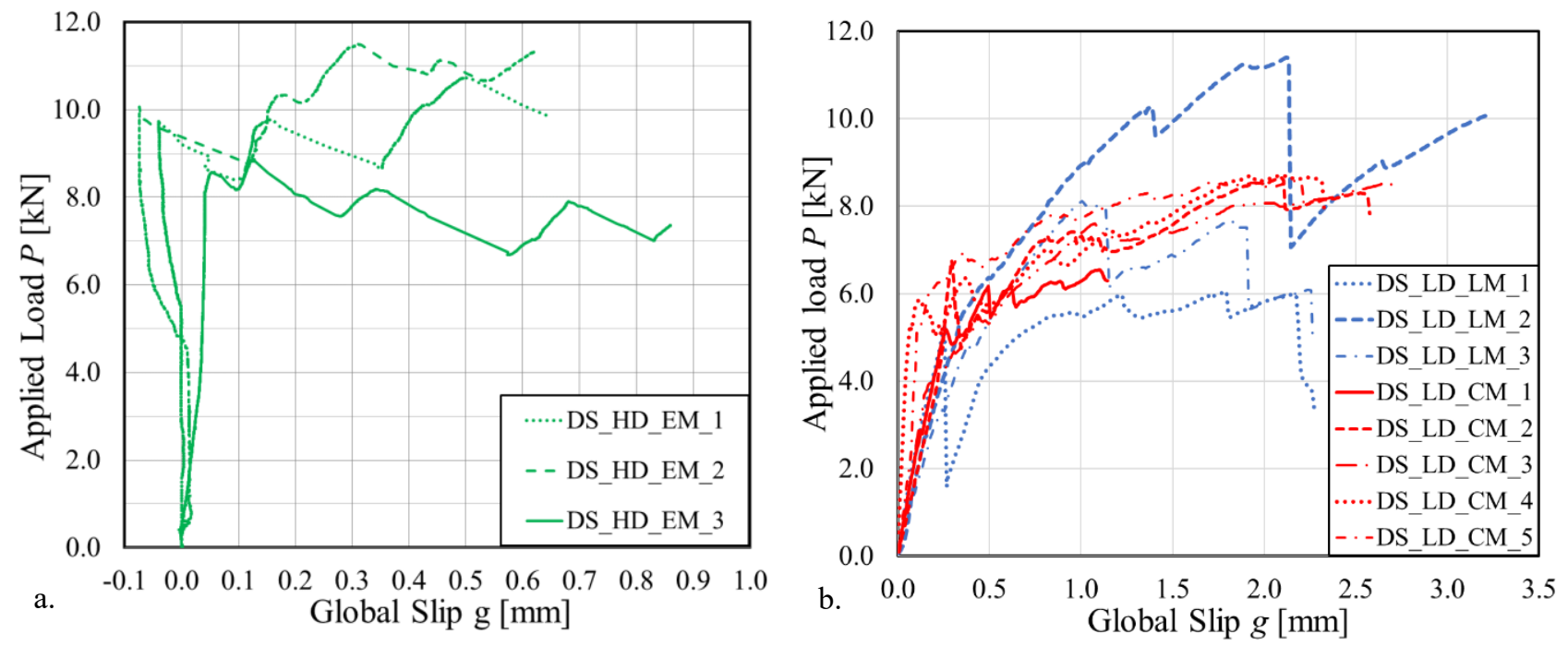

Figure 2. Test results: SRP specimens (a) and SRG specimens (b).

The failure modes of the direct shear tests are shown in Fig. 3 for representative specimens. Three different failure modes were observed: A) debonding of the composite strip with a thin layer of masonry attached to the strip (SF); B) interlaminar failure with debonding at the matrix-fiber interface (MF); C) a mixed mode failure characterized by both type A and type B failures (SF/MF). SRP specimens are characterized by type A failure mode, while almost all SRG specimens are characterized by type B failure mode. Only for specimen DS_LD_CM_1 a mixed failure mode (SF/MF) was observed.
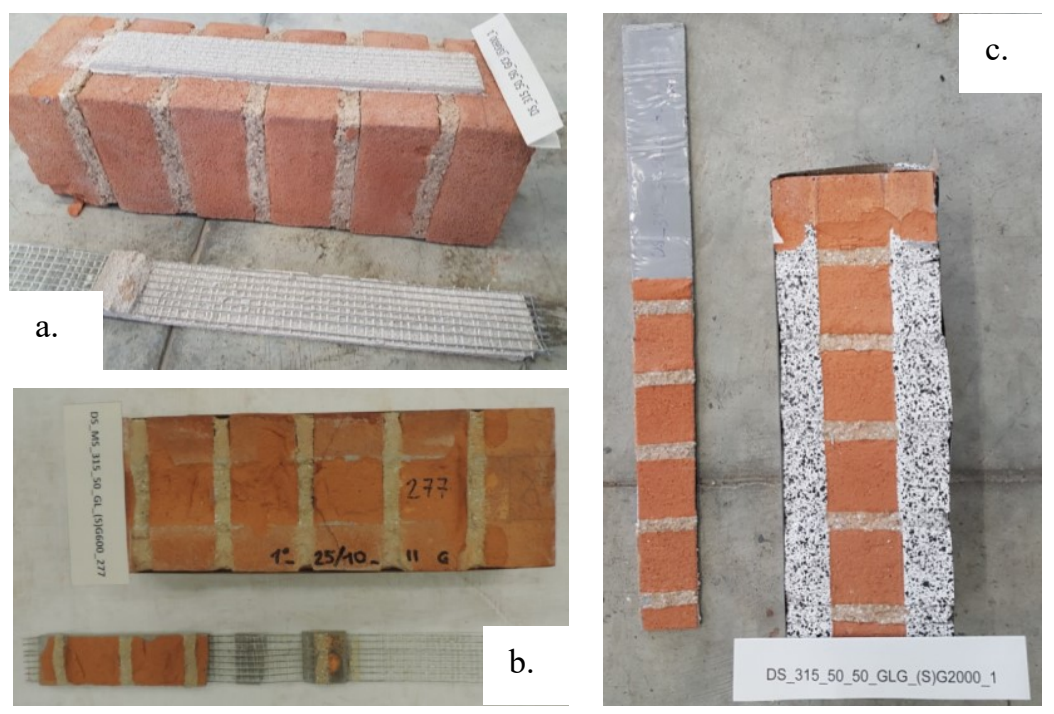

Figure 3. Representative failure modes: a) Type B, b) Type C, and c) Type A. 
Test results are summarized in Table 3, which reports for each SRG specimen the value of $P^{*}, P_{\text {crit }}, g_{1}, g_{2}$, and the failure mode. In addition, the average measurement of LVDT $\mathrm{c}$ and $\mathrm{d}$ within the global slip range $\left[g_{1}, g_{2}\right]$ is reported in Table 3 and referred to as $w$. The value $w$ provides a measure of the out of plane displacement of the masonry block when the single-lap direct shear tests were performed, which is related to the inherent eccentricity of the test set-up [11]. For all SRP specimens, it was not possible to define a constant plateau, due to the presence of periodic drops in the load response, therefore the values of $P_{\text {crit, }} g_{1}, g_{2}$, and $w$ were not reported. Also for specimen S_LD_LM_2 the constant plateau was not present. From Table 3, it can be observed that for SRG specimens, results obtained using a cement-based mortar are less scattered than results obtained using a lime-based mortar. The average plateau load obtained for specimens strengthened with a lime-based mortar and with a cement-based mortar is equal to $6.2 \mathrm{kN}(\mathrm{CoV} 0.10)$ and $7.6 \mathrm{kN}(\mathrm{CoV} 0.11)$, respectively. Therefore, employing a cement-based mortar matrix it is possible to reach a higher debonding load than specimens that employ a lime-based mortar. Results obtained for SRP specimens can be compared with the ones obtained for SRG specimens supposing that the Mode-II fracture energy of the masonry substrate can be assumed as a constant value. Using the formula proposed by [13], it is possible to predict the peak load of an SRP specimen strengthened with $L D$ steel fibers, $P_{L D}^{*}$, starting from the experimental value obtained from HD steel fibers, $P_{H D}^{*}$

$$
P_{L D}^{*}=P_{H D}^{*} \sqrt{\frac{t_{f, L D}}{t_{f, H D}}}
$$

Where $t_{f, L D}$ and $t_{f, H D}$ are the equivalent thickness for LD and HD steel fibers, respectively. The average value of the peak load for SRP specimens strengthened with LD steel fibers, employing the results of Table 3 and Eq. (1), resulted equal to $6.0 \mathrm{kN}$. This value is lower than the average peak values obtained for SRG specimens that were equal to $8.5 \mathrm{kN}$ and $8.3 \mathrm{kN}$ using a lime-based mortar and a cement-base mortar, respectively.

Table 3. Test results for SRP and SRG specimens.

\begin{tabular}{|c|c|c|c|c|c|c|}
\hline Specimen & $P^{*}[\mathrm{kN}]$ & $P_{\text {crit }}[\mathrm{kN}]$ & $g_{1}[\mathrm{~mm}]$ & $g_{2}[\mathrm{~mm}]$ & $w[\mathrm{~mm}]$ & Failure Mode \\
\hline DS_HD_EM_1 & 10.73 & $/$ & $/$ & $/$ & $/$ & SF \\
\hline DS_HD_EM_2 & 11.50 & $/$ & $/$ & $/$ & $/$ & SF \\
\hline DS_HD_EM 3 & 8.86 & $/$ & $/$ & $/$ & $/$ & SF \\
\hline DS_LD_LM_1 & 6.07 & 5.75 & 1.33 & 2.18 & 1.33 & MF \\
\hline DS_LD_LM_2 & 11.40 & $/$ & $/$ & $/$ & $/$ & MF \\
\hline DS_LD_LM_3 & 8.12 & 6.65 & 1.15 & 2.26 & 0.87 & MF \\
\hline DS_LD_CM_1 & 6.83 & 6.17 & 0.65 & 1.10 & 1.24 & SF/MF \\
\hline DS_LD_CM_2 & 8.66 & 7.85 & 0.98 & 2.55 & 0.30 & MF \\
\hline DS_LD_CM 3 & 8.55 & 7.86 & 1.20 & 2.60 & 1.65 & MF \\
\hline DS_LD_CM_4 & 8.72 & 7.97 & 0.90 & 2.30 & 1.52 & MF \\
\hline DS_LD_CM_5 & 8.59 & 8.30 & 0.98 & 2.20 & 1.41 & MF \\
\hline
\end{tabular}

\section{Conclusions}

This paper presented the results of an experimental study carried out to understand the behavior of steel reinforced polymer (SRP) and steel reinforced grout (SRG) composite strips bonded to a masonry substrate. The following conclusions can be drawn: 
1. The failure mode depends on the type of composite applied to the masonry substrate. The failure of SRP specimens is usually characterized by a cohesive crack that propagates in the masonry substrate, while the failure of SRG specimens is generally characterized by a detachment at the matrix-fiber interface.

2. A comparison between SRP specimens and SRG specimens showed that, considering the same density of the fiber sheets, SRG specimens have better performances than SRP specimens.

3. Specimens strengthened with a cement-based mortar shows a slight increase of the plateau load with respect to specimens strengthened with a lime-based mortar.

4. Due to the scatter of the load responses, additional tests will be performed in order to validate the experimental results. The additional tests will include cyclic tests on SRG and SRP-masonry joints in order to investigate the dynamic behavior of these newly developed strengthening systems during earthquakes.

\section{Acknowledgments}

The experimental work presented in this paper was conducted in the laboratory of structural and geotechnical engineering (LISG) at the University of Bologna. Staff and technicians of LISG are gratefully acknowledged. Kerakoll S.p.A., Sassuolo, Italy, is gratefully acknowledged for providing the composite materials. Financial support by the Italian Ministry of Education, Universities and Research MIUR is gratefully acknowledged (PRIN2015: "Advanced mechanical modeling of new materials and structures for the solution of 2020 Horizon challenges", prot. 2015JW9NJT 018).

\section{References}

[1] A. Borri, P. Casadei, G. Castori and J. Hammond, "Strengthening of brick masonry arches with externally bonded steel reinforced composites," Journal of composites for construction, vol. 13(6), pp. 468-475, 2009.

[2] R. Capozucca, "Experimental FRP/SRP-historic masonry delamination," Composite structures, vol. 92(4), pp. 891-903, 2010.

[3] E. Grande, M. Imbimbo and E. Sacco, "Bond behavior of historical clay bricks strengthened with steel reinforced polymers (SRP)," Materials, vol. 4(3), pp. 585-600, 2011.

[4] M. R. Valluzzi, D. V. Oliveira, A. Caratelli, G. Castori, M. Corradi, G. de Felice, E. Garbin, D. Garcia, L. Garmendia, E. Grande, U. Ianniruberto, A. Kwiecień, M. Leone, G. P. Lignola and P. B. Lourenço, "Round robin test for composite-to-brick shear bond characterization," Materials and Structures, vol. 45(12), pp. 1761-1791, 2012.

[5] G. de Felice, S. De Santis, L. Garmendia, B. Ghiassi, P. Larrinaga, P. B. Lourenço, D. V. Oliveira, F. Paolacci and C. G. Papanicolaou, "Mortar-based systems for externally bonded strengthening of masonry," Materials and structures, vol. 47(12), pp. 2021-2037, 2014.

[6] M. Santandrea, I. A. O. Imohamed, C. Carloni, C. Mazzotti, S. de Miranda and F. Ubertini, "A study of the debonding mechanism in steel and basalt FRCM-masonry joints," in Brick and Block Masonry: Proceedings of the 16th International Brick and Block Masonry Conference, Padova, Italy, 26-30 June 2016, Padova, 2016.

[7] M. Santandrea, G. Daissè, C. Mazzotti and C. Carloni, "An Investigation of the Debonding Mechanism between FRCM Composites and a Masonry Substrate," Key Engineering Materials, vol. 747, pp. 382-389, 2017.

[8] S. De Santis, F. Ceroni, G. de Felice, M. Fagone, B. Ghiassi, A. Kwiecien, G. P. Lignola, M. Morganti, M. Santandrea, M. R. Valluzzi and A. Viskovic, "Round Robin Test on tensile and bond behaviour of Steel Reinforced Grout systems," Composites Part B: Engineering, vol. 127, pp. 100-120, 2017.

[9] CEN, EN 772-1, 2011, "Methods of test for masonry units - Part 1: Determination of compressive strength. A1:2015".

[10] Kerakoll S.p.A., "www.kerakoll.com," [Online]. [Accessed November 2017]. 
[11]F. Focacci and C. Carloni, "Periodic variation of the transferable load at the FRP-masonry interface," Composite Structures, vol. 129, pp. 90-100, 2015.

[12] T. D'Antino, L. H. Sneed, C. Carloni and C. Pellegrino, "Effect of the inherent eccentricity in single-lap directshear tests of PBO FRCM-concrete joints," Composite Structures, vol. 142, pp. 117-129, 2016.

[13]B. Täljsten, "Plate bonding: Strengthening of existing concrete structures with epoxy bonded plates of steel or fibre reinforced plastics," Doctoral dissertation, Luleå tekniska universitet, 1994. 